\title{
Endogenous Uncertainty and the Non-neutrality of Money*
}

\author{
Maurizio Motolese ${ }^{\dagger}$ \\ Università Cattolica di Milano
}

April 5, 2002

\begin{abstract}
We study some implications of the Theory of Rational Beliefs to monetary policy. We show that monetary policy in a Rational Beliefs environment can have an important effect on the characteristics of economic fluctuations. In Rational Beliefs Equilibria money is generically non-neutral unlike Rational Expectations Equilibria in which money is neutral and monetary policy is ineffective. Under Rational Beliefs Equilibria nominal prices and real output change not only in response to changes in the exogenous growth rate of money but also in response to changes in the state of beliefs. In Rational Beliefs Equilibria monetary shocks have real effects even when they are observed but are not fully anticipated. Furthermore, the non-neutrality of money results in a short run Phillips curve. When money "flutters, real output sputters" [8]. We show that Endogenous Uncertainty and the distribution of market beliefs are the major explanatory variables of such fluctuations.

Under Rational Expectations monetary policy is ineffective because agents neutralize it by predicting correctly the effect of the policy. Under Rational Beliefs it is shown instead that inflation and recessions can be substantially aggravated by the distribution of market beliefs.
\end{abstract}

Keywords and Phrases: Money non-neutrality, Monetary Policy, Rational Expectations, Rational Beliefs, Rational Belief Equilibrium, Endogenous Uncertainty, States of Belief, Phillips Curve.

\section{JEL Classification Numbers: D5, D84, E52}

${ }^{*}$ I would like to thank Mordecai Kurz for his constant help and support. Most of the ideas developed hereby have been inspired by innumerable and fruitful discussions with him. I have also greatly benefited from helpful comments by Stanley Black, Luigi Campiglio, Carsten Nielsen and Ho-Mou Wu. I also received valuable remarks from participants at the V meeting of "The Society for the Advancement of Economic Theory" held in Ischia, Italy, on July 2-8, 2001, where an initial draft of the present work was presented. All errors are of course my own.

†Corresponding Address: Istituto di Politica Economica, Università Cattolica di Milano, via Necchi 5, 20123 Milano, Italy, (e-mail: maurizio.motolese@mi.unicatt.it). 


\section{Introduction.}

The work reported in this paper is a positive application of the Theory of Rational Belief Equilibrium (in short RBE) to investigate and understand the nature of money non-neutrality and its effects on the real economy. Given the expectational perspective proposed by the Theory of RBE, we show that one of the most important role in the emerging of money non-neutrality is played by endogenous uncertainty, the internally propagated uncertainty about endogenous variables such as beliefs and actions of other agents and prices. We also show that the heterogeneity of beliefs together with the distribution and intensity of agents' states of optimism/pessimism can expand or reduce the real effect of monetary policy and generate Endogenous Fluctuations of Output. This, in contrast to the Rational Expectations results of money neutrality and policy ineffectiveness, leads to a scenario in which monetary policy has an impact on the real economy by affecting motives and decisions. This view is not new to economists. J.M. Keynes already rejected the money neutrality presumption and wrote:

"...An economy, which uses money but uses it merely as a neutral link between transactions in real things and real assets and does not allow it to enter into motives or decisions, might be called - for want of a better name - a real-exchange economy. The theory which I desiderate would deal, in contradistinction to this, with an economy in which money plays a part of its own and affects motives and decisions and is, in short, one of the operative factors in the situation, so that the course of events cannot be predicted, either in the long period or in the short, without a knowledge of the behavior of money between the first state and the last. And it is this which we ought to mean when we speak of a monetary economy". (J.M. Keynes [10] pp. 408, 409).

The New Classical Economics discarded this perspective and insisted on the neutrality property of money. One can find early assertions of the neutrality of money in writings regarding monetary issues several hundred years ago. Untill the late 1960's the neutrality proposition was merely regarded as a general principle following from the Quantity Theory of Money. No precise account of the role of expectations was given to support such a proposition. With Lucas [25] money neutrality began to be viewed as an "expectational" phenomenon. Under Rational Expectations money is neutral because it is common knowledge that all agents expect the equilibrium price function to exhibit neutrality. The neutrality theory, developed by Lucas [25], Sargent and Wallace [36] often referred to as LSW proposition, states that any anticipated monetary shock would have no effect on real economic variables neither in the short run nor in the long run. Based on their theory of Rational Expectations, New Classical economists believe in the idea of policy irrelevance. In other words, since individuals hold Rational Expectations, they conclude that fully anticipated monetary policies 
are ineffective in the short run, as well as in the long run; only unanticipated policy shocks can influence real variables in the short run while in the long run the classical neutrality proposition holds. Empirical evidence has not supported such a conclusion: Mishkin [29], using quarterly data for the United States for the period 1954-1976, conclude that both anticipated and unanticipated monetary policy have a long lasting effect on output. Similar conclusions on United States and five additional countries are reached by Hoffman and Schlagenhauf [9]. Aware of the empirical evidence of money non-neutrality, early studies of monetary policy under Rational Expectations Equilibrium (in short REE) focused on informational imperfections. Lucas' [25] argued that money is not neutral because, due to asymmetric information, people confuse changes in absolute price level for changes in relative prices. Lucas' [25] turned out to be one of the most celebrated papers about monetary theory. It received widespread attention from economists: it has been regarded as the flagship of the Rational Expectations revolution. One of the main results that drew the attention of economists in Lucas [25] has been the emergence of

"the Phillips curve not as an unexplained empirical fact, but as a central feature of the solution to a general equilibrium system." (Lucas [25] p. 122)

However he also showed that the non zero slope of this curve has no use for policy purposes. That is, monetary policy (of his $k$-percent type) is neutral in his model. To strengthen this result he also claimed that the equilibrium allocation of his model with a Friedman-like monetary policy is Pareto-optimal.

The Rational Expectations approach dominated almost all economic thought in the 1970's and early 1980's. However, some concerns were raised: Chiappori and Guesnerie [6] proves the existence of a new class of non-linear solutions to the Lucas' [25] model which exhibit the non-neutrality property. In fact, under those solutions the labor-supply process is non-stationary and strongly affected by the money stock. Concern about the validity of the LSW proposition has also been raised by the theoretical sunspots literature. Azariadis [2], Azariadis and Guesnerie [3], Cass and Shell [5] and others show that money can be nonneutral in a wide class of models in which equilibrium depends on the realization of such random variables as sunspots which have no inherent relevance to the fundamentals of the economy. Some more concerns have as well been raised in a recent paper by Woodford [37] who shows that money non-neutrality can emerge as a simple consequence of the failure of common knowledge of monetary shocks to hold at any level of the chain of reasoning. This shows even further how much expectations are at the foundation of any theory of non-neutrality.

We note that when agents hold diverse beliefs the LSW neutrality proposition need not to hold in equilibrium. An equilibrium in which rational agents hold diverse beliefs is one where they have subjective theories about the dynamics of the economy. In particular, in an RBE agents have a non-stationary perspective 
on the economy hence they hold different opinions about the true probability distributions of the equilibrium stochastic process of exogenous and endogenous variables (i.e. they hold different conditional probabilities). It follows agents arrive at different conclusions when they condition their probability beliefs on current information. That is, agents interpret current information differently. Hence, even fully observed monetary shocks could be interpreted differently by agents and money non-neutrality is implied (for earlier results see Motolese [30], [31] and Kurz, Jin and Motolese [21]). Furthermore, the non-neutrality of money under RBE results in the emergence of a short run Phillips curve. The non-zero slope of this curve in the monetary equilibria with diverse beliefs, in spite of Lucas' [25] conclusion, opens up the door to a crucial role for monetary policy as explained in Kurz, Jin and Motolese [21].

The rest of the paper is organized as follows. Section 2 presents a brief review of Lucas' [25] model and results. Section 3 formalizes the OLG models at study, defines both the REE and the RBE and reports and discusses the simulated results of money neutrality/non-neutrality and the real effects of monetary policy and state of beliefs. Section 4 examines the endogenous GNP fluctuations and the Phillips curve results of our model. Section 5 concludes.

\section{Review of Lucas Model.}

Lucas' [25] model of money neutrality was, for a time, very influential and contributed to the development of the Rational Expectations literature on economic policy. However, its empirical and theoretical relevance, as we mentioned above, has been later subjected to strong criticism. We use it in the present paper, which is methodological in nature, only insofar as it simplifies the analysis and allows a better understanding of how a monetary RBE works. Nevertheless, as we explain in Section 3, we depart from Lucas' [25] model in three fundamental ways: (i) trading occurs on one single competitive market thus we relax the assumption of separate isolated markets; (ii) monetary policy is observed by all agents hence we relax the Lucas' [25] assumption of asymmetric information; (iii) agents' do not hold Rational Expectations but heterogeneous conditional Rational Beliefs. We now turn to a brief review of Lucas' [25] model.

The structure of the model is very simple. It is an Overlapping Generation model where agents live for two periods. At each date $t, N$ identical agents are born and hence at each date $2 N$ (divisible) agents are present in the economy. When young they make consumption and labor supply decisions over the two periods of their life. They supply $n_{t}$ units of labor ( per capita) only when young producing the amount $y_{t}=n_{t}$ of consumption good. Since agents are only productive in the first period of their life (when young) and the consumption good is not storable, in order to consume in the second period of their life (when old) they have to hold money. All agents have identical preferences and rational 
expectations in the sense of Muth [32]. Trading occurs on two competitive geographically isolated markets ${ }^{1}$ without any trading occurring between them and without information exchange between them as well. At each date $t$ the young agents are allocated randomly across the two markets in the proportions $\theta_{t} / 2$ and $\left(1-\theta_{t} / 2\right)$, respectively, where $\left\{\theta_{t}, t=1,2, \ldots\right\}$ are independently and identically distributed random variables with continuous symmetric density function $g$ on $(0,2)$. The old generation is allocated in such a way that each market possesses at all times one-half the aggregate supply of money. The two markets are treated symmetrically hence an equilibrium can be computed by looking at just one of them.

Fiat money is issued by a government and is transferred to the old agents at the beginning of each period. The transfer is assumed to be proportional to the pre-transfer holdings of the agents. Let $\bar{m}_{t}$ denote the pre-transfer money holdings, per old agent, at date $t$. All agents know $\bar{m}_{t}$ as well as the ruling price $p_{t}$ on their own island and all past prices. Post transfer money holdings, per old agent, are given by the equation

$$
\bar{m}_{t+1}=\bar{m}_{t} x_{t}
$$

where $\left\{x_{t}, t=1,2, \ldots\right\}$ are independently and identically distributed random variables with continuous density function $f$ on $(0, \infty)$. To rule out wealth redistribution effect, it is assumed that $x_{t}$ is common to all old agents. The state of the economy at any date $t$ is then completely described by the three variables $\left(\bar{m}_{t}, x_{t}, \theta_{t}\right)$ and the motion from state to state is independent of decisions made by agents and completely determined by equation (1), and by the density functions $g$ and $f$. There is no inheritance. Old agents do not have any labor to sell and money does not yield any direct utility. At the start of trading at date $t$ young agents do not observe the monetary policy variable $x_{t}$ as well as the real shock random variable $\theta_{t}$. Since the observed price $p_{t}$ responds to both nominal and real shocks, all the additional information about the actual state of the economy hide in a noisy price message. Asymmetry of information is assumed as at the beginning of trading at each date $t$ all old agents possess more information than young agents. In fact, by the mere fact of receiving a transfer of money proportional to their pre-transfer holdings, they do observe $x_{t}$. Some monetary policy $x_{t}$ is implemented and yet it is not public information. Furthermore, such valuable information for young agents is completely valueless to old agents who simply give up their cash balances in return for as much consumption as they can buy at market price.

The young agent's utility, measured by a Von Neumann-Morgestern utility

\footnotetext{
${ }^{1}$ In the following literature this type of model has been explicitly referred to as the twoisland model (see Lucas [26]). In Azariadis [2] the two markets are named, in a very colorful way, Pacifica and Atlantica
} 
function which has the form

$$
U\left(c_{t}, n_{t}\right)+V\left(c_{t+1}\right)
$$

depends on consumption $c_{t}$, supply of labor $n_{t}$ at date $t$ and consumption $c_{t+1}$ at date $t+1$. Let $\lambda_{t}$ denote the young agent's demand for money at date $t$, which is the money holdings he is carrying over into next period and which will then be affected by the monetary shock at date $t+1$. Then his consumption at date $t+1$ will be $c_{t+1}=\left(x_{t+1} \lambda_{t} / p_{t+1}\right)$. Let $x_{t+1}$ and $p_{t+1}$ have the joint conditional distribution function $F\left(x_{t+1}, p_{t+1} \mid \bar{m}_{t}, p_{t}\right)$, then the decision problem of the young agent is to choose a non-negative triple $\left(c_{t}, n_{t}, \lambda_{t}\right)$ to maximize his expected utility function:

$$
U\left(c_{t}, n_{t}\right)+\int V\left(\frac{x_{t+1} \lambda_{t}}{p_{t+1}}\right) d F\left(x_{t+1}, p_{t+1} \mid \bar{m}_{t}, p_{t}\right)
$$

subject to the budget constraint:

$$
p_{t} c_{t} \leq p_{t} n_{t}-\lambda_{t}
$$

In the market where the fraction $\theta_{t} / 2$ of young agents is allocated at date $t$, if the state of the economy is $\left(\bar{m}_{t}, x_{t}, \theta_{t}\right)$, the total demand for consumption good by the old agents is $\left(N \bar{m}_{t} x_{t} / 2 p_{t}\right)$. Young agents choose their net good supply functions $\left(n_{t}-c_{t}\right)=\xi\left(p_{t} ; F\left(x_{t+1,} p_{t+1} \mid \bar{m}_{t}, p_{t}\right)\right)$. The total net good supply is then $N \theta_{t} \xi() / 2$ and the consumption good market will clear if

$$
\left(N \bar{m}_{t} x_{t} / 2 p_{t}\right)=N \theta_{t} \xi\left(p_{t} ; F\left(x_{t+1,} p_{t+1} \mid \bar{m}_{t}, p_{t}\right)\right) / 2 \text {, }
$$

that is

$$
\bar{m}_{t} x_{t} / \theta_{t}=p_{t} \xi\left(p_{t} ; F\left(x_{t+1,} p_{t+1} \mid \bar{m}_{t}, p_{t}\right)\right) .
$$

By Walras' law, equilibrium on the money market is also obtained once the market clearing condition (6) is satisfied. On the money market the total money supplied by the old agents is $\left(N \bar{m}_{t} x_{t} / 2\right)$, hence the money supplied per demander is $\left(N \bar{m}_{t} x_{t} / 2\right) /\left(N \theta_{t} / 2\right)=\bar{m}_{t} x_{t} / \theta_{t}$ and in equilibrium $\lambda_{t}=\bar{m}_{t} x_{t} / \theta_{t}$.

The equilibrium price is a function, that is, a time invariant rule of the form $p=\Psi(\bar{m}, x, \theta)$ that relates the price level to the exogenous shocks $(x, \theta)$ and to the pre-transfer money holdings $\bar{m}$. The price function $\Psi$ is known to all agents, although they do not observe $x$ and $\theta$. The true probability distribution of next period's price, $p^{\prime}=\Psi\left(\bar{m}^{\prime}, x^{\prime}, \theta^{\prime}\right)=\Psi\left(\bar{m} x, x^{\prime}, \theta^{\prime}\right)$ is known, conditional on $\bar{m}$, from the known distribution of $x, x^{\prime}$ and $\theta^{\prime}$. Agents, treating $\bar{m}$ as parameter, take expectations with respect to the well-defined joint distribution of $\left(x, x^{\prime}, \theta^{\prime}\right)$ conditional on $\Psi(\bar{m}, x, \theta)$ denoted in Lucas' paper by $G\left(x, x^{\prime}, \theta^{\prime} \mid \Psi(\bar{m}, x, \theta)\right)$, hence dispensed with unspecified distribution $F$. Returning to the exogenous shocks $(x, \theta)$, from the form of the market clearing condition (6) and in view of 
Lemma 1 in Lucas $([25]$, p. 111), it is easy to see that they affect the economy only through their ratio $z=x / \theta$. Hence the market clearing price function $p=\Psi(\bar{m}, x, \theta)$ can be rewritten as $p=\Psi(\bar{m}, z)$. Under the a priori neutrality-like hypothesis that the state variable $\bar{m}$ affects equilibrium prices in proportion and quantities are not affected at all, the equilibrium price function is then rewritten as $p=\Psi(\bar{m}, x, \theta)=\bar{m} \varphi(z)$. Lucas [25] assumes that $\bar{m}$ and $\varphi(z)$ are known to the agents. He then proves that $\varphi(z)$ is monotonic in $z=x / \theta$ (see Lemma 1 in Lucas $[25]$, p. 111$)^{2}$. Hence if agents observe the price $p$ they can deduce the value of the ratio $z=x / \theta$. If neither $x$ nor $\theta$ are observed by agents, knowledge of the ratio $z=x / \theta$ still leads to confusion between relative and absolute prices. Indeed, under these conditions, money is non-neutral in Lucas' model. On the other hand, when either $x$ or $\theta$ are observed by agents, price signals are not noisy and consequently all nominal movements are only reflected in the absolute level of prices. That is, money is neutral. In the case where the exogenous shock to the economy is not a purely monetary one, Lucas finds a positive price function with elasticity between zero and one. This implies that the equilibrium employment function has the form $n(x / \theta)$ and that $n^{\prime}(x / \theta)>0$. That is, increases in demand induce increases in real output, weather the initial increase in demand is monetary (an increase in $x$ ) or real ( a reduction in $\theta$ ). At this point the relevance to the Phillips curve debate is clear. In Lucas' model there is no usable trade-off between inflation and employment and yet in equilibrium inflation and employment appear to have positive correlation.

\section{Money non-neutrality under Rational Beliefs.}

\subsection{The model and its stochastic structure.}

We now consider the same monetary economy studied by Lucas [25] and compute equilibria with the perspective of the theory of RBE and show how money nonneutrality arises from the perspective of this theory. The economy is studied by use of an Overlapping Generation model where agents live for two periods. At each date $t, N$ agents are born within each of the $K$ agent-types present in the economy and hence at each date $2 N K$ agents ( $N$ young and $N$ old for each one of the $K$ agent-types) are present in the economy. Generally within each agent-type the $N$ agents might have the same utility and hold different conditional beliefs. This is the case of social states of beliefs studied in Kurz [18]. In the present study we concentrate on the extreme case in which the beliefs of the agents are perfectly correlated within each agent-type hence agents of the same type hold

\footnotetext{
${ }^{2}$ Following Lucas' erratum [27] and relaxing the a priori neutrality-like hypothesis, Chiappori and Guesnerie [6] found a broader class of non-neutral solutions to the price function $p=$ $\Psi(\bar{m}, x, \theta)=\psi(\bar{m}, z)$ with $z=x / \theta$.
} 
the same conditional beliefs. ${ }^{3}$

We now turn to our monetary model of perfectly correlated beliefs within each agent type. Note that this economy has the same results of an economy where only $2 K$ agents ( $K$ young and $K$ old) are present. We then proceed as if only $K$ agents are born at each date $t$. To describe our model we first introduce some notation.

$l_{t}^{k} \quad$ - consumption of leisure by the young agent $k$ at $t$,

$C_{t}^{k}$ - consumption of commodities by the old agent $k$ at $t$,

$m_{t}^{k}$ - money holdings of the young agent $k$ at $t$,

$P_{t} \quad$ - price of consumption good at date $t$,

$M_{t}$ - money supply at date $t$,

$g_{t} \quad$ - production of consumption good by the young agent $k$ at $t$,

$I_{t} \quad$ - information available at $t$.

When young, agents make consumption and labor supply decisions over the two period of their life. It is assumed as in Azariadis [2] that in the first period of their life (when young) agents do not consume any consumption good. They just supply $\left(1-l_{t}\right)$ units of labor (per capita) producing the amount $g_{t}=\left(1-l_{t}\right)$ of consumption good. We do not follow Lucas [25] in creating informationally isolated markets. We assume that trading occurs on a single competitive market. Young agents supply $\left(1-l_{t}\right)$ units of labor (per capita). At each date $t$ an exogenous shock $\theta_{t}$ impacts on young agents'productivity, where $\left\{\theta_{t}, t=1,2, \ldots\right\}$ is a stationary Markov process that will be specified below. Hence, at each date $t$ each young agent produces the amount $g_{t}=\theta_{t}\left(1-l_{t}\right)$ of consumption good. Since agents are only productive in the first periods of their life (when young) and the consumption good is not storable, in order to consume in the second period of their life (when old) they have to hold money.

Fiat money is issued by a government and is transferred to the old agents at the beginning of each period. Let $M_{t-1}$ denote the aggregate pre-transfer money holdings, that is the aggregate money purchased by the agents at $t-1$ (when young) and carried over next period at date $t$ (when old). Then the aggregate post-transfer money holdings at date $t$ are given by the equation

$$
M_{t}=M_{t-1} x_{t}
$$

where $\left\{x_{t}, t=1,2, \ldots\right\}$ is a stationary Markov process that will be specified below. The money increase/decrease $\Delta M_{t}=M_{t}-M_{t-1}=M_{t-1}\left(x_{t}-1\right)$ is hence transferred to the old agents. We adopt helicopter money as it is in Lucas [25], hence the transfer is proportional to the pre-transfer holdings of the agents. Diverging from Lucas [25], no asymmetry of information is assumed in our model; indeed we assume that, at date $t, x_{t}$ and $\theta_{t}$ are observed by all agents. This

\footnotetext{
${ }^{3}$ For a better understanding of the notation and terminology used here see chapter 3 in Motolese [30] or Kurz [14].
} 
is equivalent to say that once the monetary policy at date $t$ is announced it is known to all agents. Under these assumptions in Lucas' model with proportional transfers money is neutral. This is not the case under Rational Beliefs where, though agents observe $x_{t}$ and $\theta_{t}$, money is generically non-neutral.

At all dates the aggregate stock of money, the total demand for consumption by the old agents is $M_{t} t=1,2, \ldots$. Young agents choose their net good supply functions

$$
g_{t}^{k}=\theta_{t}\left(1-l_{t}^{k}\right) \quad t=1,2, \ldots
$$

The aggregate good supply is then

$$
\theta_{t}\left(K-\sum_{k=1}^{K} l_{t}^{k}\right) \quad t=1,2, \ldots
$$

Hence in equilibrium we shall have

$$
M_{t}=P_{t} \theta_{t}\left(K-\sum_{k=1}^{K} l_{t}^{k}\right) \quad t=1,2, \ldots
$$

To make the equilibrium solutions independent of the initial money supply at date $0, M_{0}$, define $p_{t}=P_{t} / M_{t-1}$ and $p_{t+1}=P_{t+1} / M_{t}$ which by equation (7) can be written as $p_{t+1}=P_{t+1} / M_{t-1} x_{t}{ }^{4}$ This allows us to satisfy the stability conditions in the sense of Kurz [12].

In equilibrium inflation rates for all transitions from $t$ to $t+1$ are defined by

$$
1+i_{t+1}=\frac{P_{t+1}}{P_{t}} \quad t=1,2, \ldots
$$

and using the definition, given above, of $p_{t}$ and equation (7) we redefine them by

$$
1+i_{t+1}=\frac{x_{t} p_{t+1}}{p_{t}} \quad t=1,2, \ldots
$$

At each date $t$ the young agents make an allocative decision with full knowledge of their labor endowment, the price level, the real exogenous shock $\theta_{t}$ and the observed monetary policy $x_{t}$. However they are uncertain about the future price level $P_{t+1}$ that will be realized when they are old. Therefore they are uncertain about the future rate of return on their labor which is defined by

$$
1+r_{t+1}=\frac{P_{t} x_{t+1}}{P_{t+1}} \quad t=1,2, \ldots
$$

and using the definition, given above, of $p_{t}$ and equation (7) it can be redefined by

$$
1+r_{t+1}=\frac{p_{t} x_{t+1}}{x_{t} p_{t+1}} \quad t=1,2, \ldots
$$

\footnotetext{
${ }^{4}$ To simplify notation in the rest of the section we call the ratios $p_{t}=P_{t} / M_{t-1}$ prices.
} 
Note that the interest factor $1+r$ can be also interpreted as a wage rate.

The stochastic structure of the model consists of: the process of money growth $\left\{x_{t}, t=1,2, \ldots\right\}$ where $x_{t} \in X$, the process of exogenous productivity shocks $\left\{\theta_{t}, t=1,2, \ldots\right\}$ where $\theta_{t} \in \Theta$ and of the process of the agents' assessment variables denoted by $y_{t}=\left(y_{t}^{1}, y_{t}^{2}, \ldots, y_{t}^{k}\right) \in Y \equiv Y^{1} \times Y^{2} \times \ldots \times Y^{k}$. The state of the economy at any date $t$ is then entirely described by $\left(x_{t}, \theta_{t}, y_{t}\right)$.

Assumption $1 X$ is a finite subset in $\mathbb{R}_{++}$with $|X|$ elements; the exogenous process $\left\{x_{t}, t=1,2, \ldots\right\}$ is a stable ${ }^{5}$ Markov process on $X$ with probability measure $\Pi_{X}$ defined on $\left(X^{\infty}, \mathbb{B}\left(X^{\infty}\right)\right)$ with stationary measure $m_{X}$.

Assumption $2 \Theta$ is a finite subset in $(0,2)$ with $|\Theta|$ elements; the exogenous process $\left\{\theta_{t}, t=1,2, \ldots\right\}$ is a stable Markov process on $\Theta$ with probability measure $\Pi_{\Theta}$ defined on $\left(\Theta^{\infty}, \mathbb{B}\left(\Theta^{\infty}\right)\right)$ with stationary measure $m_{\Theta}$.

Agents do not have structural knowledge and hence do not know the true equilibrium map between states $\left(x_{t}, \theta_{t}, y_{t}\right)$ and prices. Agents take as known at each date $t$ the past observed prices $\left(p_{1}, p_{2}, \ldots, p_{t}\right)$, the past realizations of the exogenous shocks $\left\{x_{\tau}, \tau=1,2, \ldots, t\right\}$ and $\left\{\theta_{\tau}, \tau=1,2, \ldots, t\right\}$ and they do observe past realizations of $\left\{y_{\tau}, \tau=1,2, \ldots, t\right\}$ which occur within their own life. They do not observe the assessment variables of any other agent or of their own "parents". For this reason they will never learn the true probability distribution of $x_{t}$ and $\theta_{t}$ and the true structure of the equilibrium map. Agents then form probability beliefs about prices and exogenous states knowing that the exogenous state space is a partition of the price state space. We can then write the beliefs $Q^{k}$ as probabilities on $\left(P \times Y^{k}\right)$ and then state the following

Assumption 3 For all $k$, under the belief $Q^{k}$ the process $\left\{\left(p_{t}, y_{t}^{k}\right), t=1,2, \ldots\right\}$ is jointly a Markov process and the dynamical system

$$
\left(\left(P \times Y^{k}\right)^{\infty}, \mathbb{B}\left(\left(P \times Y^{k}\right)^{\infty}\right), Q^{k}, T\right)
$$

(where $T$ is the shift transformation) is stationary and ergodic. $Y^{k}$ is a finite subset in $\mathbb{R}$ with $\left|Y^{k}\right|$ elements. The non-stationarity induced by each assessment

\footnotetext{
${ }^{5}$ Agents try to learn something about the true probability distribution $\Pi$ by observing the data generated by the economy. Let $v^{t}=\left(v_{t+1}, v_{t+2}, v_{t+3}, \ldots\right) \in V^{\infty}$ and $v=\left(v_{1}, v_{2}, v_{3}, \ldots\right) \in$ $V^{\infty}$ then the shift transformation is defined by $v^{t}=T v^{t-1}$. Agents compute $m^{n}(B)(v)=$ $\frac{1}{n} \sum_{k=0}^{n-1} 1_{B}\left(T^{k} v\right)$, the relative frequency at which the dynamical system visits each measurable set $B \in \mathbb{B}\left(V^{\infty}\right)$ given that it started at $v$, where $1_{B}(z)=\left\{\begin{array}{ll}1 & \text { if } z \in B \\ 0 & \text { if } z \notin B\end{array}\right.$.

Learning occurs only if, given sufficient data, $m^{n}(B)(v)$ converges. It hence follows that a dynamical system $\left(V^{\infty}, \mathbb{B}\left(V^{\infty}\right), \Pi, T\right)$ is said to be stable if for all finite-dimensional sets, or cylinders, $B \in \mathbb{B}\left(V^{\infty}\right), \lim _{n \rightarrow \infty} m^{n}(B)(v)=\bar{m}(B)(v) \Pi$ a.e. The system is said to be strongly stable if the limit of $m^{n}(B)(v)$ exists $\Pi$ a.e. for all $B \in \mathbb{B}\left(V^{\infty}\right)$. If the additional assumption of ergodicity is made (as we do later) then the limit above is independent of $v$. (For more details see Kurz [12] and Kurz [14]).
} 
variable $y^{k}$ is a selection, at each date, of a Markov transition function (a matrix if the set of prices is finite) which is determined by the value taken by $y_{t}^{k}$.

Further explanation of assumption 3 will be given later.

Assumption 4 The utility function of the $k^{\text {th }}$ agent is $u^{k}\left(l^{k}, C^{k}\right)$ which is $C^{2}$, strictly increasing and strictly concave.

Using the definition, given above, of $p_{t}$ we now write the optimization problem of the young agent $k$ :

$$
\max _{\left(l^{k}, C^{k}\right)} E_{Q_{t}^{k}}\left\{u^{k}\left(l_{t}^{k}, C_{t+1}^{k}\right) \mid\left(p_{t}, x_{t}, \theta_{t}, y_{t}^{k}\right)\right\}
$$

subject to

$$
\begin{gathered}
p_{t+1} C_{t+1}^{k}=\frac{m_{t}^{k} x_{t+1}}{M_{t}} \\
m_{t}^{k}=\theta_{t}\left(1-l_{t}^{k}\right) p_{t} M_{t-1}
\end{gathered}
$$

which imply that

$$
C_{t+1}^{k}=\frac{\theta_{t}\left(1-l_{t}^{k}\right) p_{t} x_{t+1}}{p_{t+1} x_{t}}
$$

The market clearing conditions are:

$$
x_{t}=p_{t} \theta_{t}\left(K-\sum_{k=1}^{K} l_{t}^{k}\right) \quad t=1,2, \ldots
$$

Under the Markov assumption, the demand function for leisure of all generations take the form

$$
l_{t}^{k}=\xi^{k}\left(p_{t}, x_{t}, \theta_{t}, y_{t}^{k}\right)
$$

and in equilibrium

$$
x_{t}=p_{t} \theta_{t}\left(K-\sum_{k=1}^{K} \xi^{k}\left(p_{t}, x_{t}, \theta_{t}, y_{t}^{k}\right)\right) .
$$

We can solve (14) and write the equilibrium map in the form

$$
p_{t}=\Phi^{*}\left(x_{t}, \theta_{t}, y_{t}\right) \quad t=1,2, \ldots
$$

Solution of the form (15) are also derived by Nielsen [33], Kurz and Schneider [23], Kurz and Wu [24], Kurz and Beltratti [20], Kurz [16], [18] and by Kurz and Motolese [22]. The state space for equilibrium analysis is $(X \times \Theta \times Y)$. Note that the number of distinct equilibrium prices cannot exceed $M=|\Theta||X| \prod_{k=1}^{K}\left|Y^{k}\right|$. 
We then conclude that in any RBE only a finite number of equilibrium prices such that

$$
p_{s}=\Phi^{*}\left(x_{s}, \theta_{s}, y_{s}\right) \text { for } s=1,2, \ldots, M
$$

is observed.

Now we have to specify the true joint distribution of private assessment variables $y_{t}, x_{t}$ and $\theta_{t}$ as a probability $\Pi_{X \Theta Y}$ on the measurable space

$$
\left((X \times \Theta \times Y)^{\infty}, \mathbb{B}\left((X \times \Theta \times Y)^{\infty}\right)\right) .
$$

Some restriction apply to the probability measure $\Pi_{X \Theta Y}$. First consider the vector $y_{t}$ of assessment variables. Each agent $k$ determines his own probability of $y_{t}^{k}$ and knows his own distribution. The probability of $y_{t}^{k}$ is $Q_{Y^{k}}^{k}$ the marginal measure of $Q^{k}$ on $Y^{k}$. Given $\Pi_{X \Theta Y}$ the implied probability of $y_{t}^{k}$ is $\Pi_{(X \Theta Y)_{Y k}}$ and the following must be satisfied:

$$
\Pi_{(X \Theta Y)_{Y^{k}}}=Q_{Y^{k}}^{k} \text { for } k=1,2, \ldots, K .
$$

Assumption 5 Under $\Pi_{X \Theta Y}$ the process $\left\{\left(x_{t}, \theta_{t}, y_{t}\right), t=1,2, \ldots\right\}$ is a Markov process and the dynamical system

$$
\left((X \times \Theta \times Y)^{\infty}, \mathbb{B}\left((X \times \Theta \times Y)^{\infty}\right), \Pi_{X \Theta Y}, T\right)
$$

is stable and ergodic with stationary measure $m_{X \Theta Y}$.

Lemma 6 The price process $\left\{p_{t}, t=1,2, \ldots\right\}$ is a stable and ergodic process on the finite state space $X \times \Theta \times Y$ with probability $\Pi_{P}$ and a stationary measure $m_{P}$. The probability $\Pi_{P}$ on $\left((P), \mathbb{B}\left((P)^{\infty}\right)\right)$ is defined by the probability $\Pi_{X \Theta Y}$ together with the equilibrium map (16). The measure $m_{P}$ is also obtained from $m_{X \Theta Y}$ and the map $\Phi^{*}$ in (16).

Now, for any set $A \in \mathbb{B}\left((X \times \Theta)^{\infty}\right)$ define $\Phi_{X \Theta}^{*}(A)=\left\{p \in(P)^{\infty}: p_{t}=\Phi^{*}\left(x_{t}\right.\right.$, $\left.\theta_{t}, y_{t}\right)$ all $t$, for $\left(x_{t}, \theta_{t}\right) \in A$, some $\left.y_{t} \in Y^{\infty}\right\}$. It then follows from the map (16) that in equilibrium we must have

$$
\Pi_{X \Theta}(A)=\Pi_{P}\left(\Phi_{X \Theta}^{*}(A)\right) \text { for all } A \in \mathbb{B}\left((X \times \Theta)^{\infty}\right)
$$

and therefore

$$
m_{X \Theta}(A)=m_{P}\left(\Phi_{X \Theta}^{*}(A)\right) \text { for all } A \in \mathbb{B}\left((X \times \Theta)^{\infty}\right) .
$$

(16), (17), (18) and (19) provide the tools for stating the rationality conditions of the agents.

The belief $Q^{k}$ is a probability on the space $\left(\left(P \times Y^{k}\right)^{\infty}, \mathbb{B}\left(\left(P \times Y^{k}\right)^{\infty}\right)\right)$ since the agent is not assumed to know the map $\Phi^{*}$. However, the data reveals that the empirical distribution of prices, money growth and productivity shocks must conform to (19) and this condition must be satisfied by $Q^{k}$ as required by the rationality axioms. The following is then implied by the Conditional Stability Theorem: 
Lemma 7 Under the assumptions of Lemma $6 Q^{k}$ is a rational belief relative to $\Pi_{P}$ if:

$$
\begin{aligned}
& \text { 1. } \Pi_{(X \Theta Y)_{Y^{k}}}=Q_{Y^{k}}^{k} \text {, } \\
& \text { 2. } Q_{X \Theta}^{k}(A)=Q_{P}^{k}\left(\Phi_{X \Theta}^{*}(A)\right)=m_{X \Theta}(A) \text { for all } A \in \mathbb{B}\left((X \times \Theta)^{\infty}\right) \text {, } \\
& \text { 3. } Q_{P}^{k}=m_{P} \text {. }
\end{aligned}
$$

Using Lemma 7 we can define a RBE as follows:

Definition $8\left\{\Pi_{P},\left\{\left(Q^{k}, l_{s}^{k}, m_{s}^{k}\right)\right.\right.$ for $k=1,2, \ldots, K$ and $\left.s=1,2, \ldots, M\right\}$ and $\left(p_{s}\right)$ for $s=1,2, \ldots, M\}$ constitute a RBE of the monetary $O L G$ economy if:

1. $Q^{k}$ is a rational belief relative to $\Pi_{P}$ for $k=1,2, \ldots, K$ and $\Pi_{P}$ is defined by $\Pi_{X \Theta Y}$ and by the equilibrium map induced by $\left(Q^{1}, Q^{2}, \ldots, Q^{k}\right)$,

2. $\left(l_{1}^{k}, l_{2}^{k}, \ldots, l_{M}^{k}\right)$ are optimal agent allocations for $k=1,2, \ldots, K$,

3. $x_{s}=p_{s} \theta_{s}\left(K-\sum_{k=1}^{K} l^{k}\right)$ for all $t$ and $s$.

Theorem 9 Under assumptions 4 and 5 there exist a $R B E$.

Proof: See proof of existence from Kurz and Schneider [23] in Kurz [14] pp. 278-282.

\subsection{Simulations of the monetary economy.}

Our main tool of analysis here is economic simulations. Such tool enables us to study dynamical systems which are complex mathematical objects for which it would be very difficult to provide a complete characterization by using only mathematical tools. The objective of all simulations is to exhibit the workings of economic principles. For instance, the simulations in the present work focus on the conditions under which the Markov monetary economy under study exhibits money non-neutrality and endogenous fluctuations. We numerically solve for equilibria and through MonteCarlo simulations we generate time series to study the real effect of monetary policy.

Now, let $K=2$. Assume a CRRA time separable utility function common to all agents with common relative risk aversion (i.e. $\gamma^{1}=\gamma^{2}=\gamma$ ). The optimization problem of agent $k$ is then stated as follows for $(k=1,2)$ :

$$
\max _{\left(l^{k}, C^{k}\right)} E_{Q_{k_{t}}}\left\{\frac{1}{1-\gamma}\left(l_{t}^{k}\right)^{1-\gamma}+\frac{\beta}{1-\gamma}\left(C_{t+1}^{k}\right)^{1-\gamma} \mid I_{t}\right\}
$$


subject to

$$
C_{t+1}^{k}=\frac{\theta_{t}\left(1-l_{t}^{k}\right) p_{t} x_{t+1}}{p_{t+1} x_{t}}
$$

Inserting (21) into (20) we can write down agent-type 1's first order conditions for optimization:

$$
\left(\frac{1-l_{t}^{1}}{l_{t}^{1}}\right)^{\gamma}=\left(\frac{\theta_{t} p_{t}}{x_{t}}\right)^{1-\gamma} \beta E_{Q_{1}}\left(\left(\frac{x_{t+1}}{p_{t+1}}\right)^{1-\gamma} \mid I_{t}\right)
$$

and agent-type 2's first order conditions for optimization:

$$
\left(\frac{1-l_{t}^{2}}{l_{t}^{2}}\right)^{\gamma}=\left(\frac{\theta_{t} p_{t}}{x_{t}}\right)^{1-\gamma} \beta E_{Q_{2}}\left(\left(\frac{x_{t+1}}{p_{t+1}}\right)^{1-\gamma} \mid I_{t}\right) .
$$

In equilibrium we must have

$$
p_{t} \theta_{t}\left(2-l_{t}^{1}-l_{t}^{2}\right)=x_{t} .
$$

Under assumptions 3 and 4 the standard theorems of dynamic programming apply to the optimization of the agents. The demand function of agent-type $k$ $(k=1,2)$ for leisure depends upon $\left(p_{t}, x_{t}, \theta_{t}, y_{t}^{k}\right)$. We can then rewrite the market clearing condition as

$$
p_{t} \theta_{t}\left(2-l_{t}^{1}\left(p_{t}, x_{t}, \theta_{t}, y_{t}^{1}\right)-l_{t}^{2}\left(p_{t}, x_{t}, \theta_{t}, y_{t}^{2}\right)\right)=x_{t} .
$$
form:

Condition (25) implies that the equilibrium map of the economy takes the

$$
p_{t}=\Phi^{*}\left(x_{t}, \theta_{t}, y_{t}^{1}, y_{t}^{2}\right) \text {. }
$$

Assumption $10 Y^{1}=Y^{2}=\{0,1\}, X=\left\{x^{H}, x^{L}\right\}$ and $\Theta=\left\{\theta^{H}, \theta^{L}\right\}$. The marginal measure of $\Pi_{X \Theta Y}$ on $\left(X^{\infty}, \mathbb{B}\left(X^{\infty}\right)\right)$ and on $\left(\Theta^{\infty}, \mathbb{B}\left(\Theta^{\infty}\right)\right)$ specify these processes to be stationary and ergodic Markov processes with transition matrices

$$
\left[\begin{array}{cc}
\chi & 1-\chi \\
1-\chi & \chi
\end{array}\right] \text { and }\left[\begin{array}{cc}
\vartheta & 1-\vartheta \\
1-\vartheta & \vartheta
\end{array}\right]
$$

respectively. Similarly, the marginal measures of $\Pi_{X \Theta Y}$ on $\left(Y^{1 \infty}, \mathbb{B}\left(Y^{1 \infty}\right)\right)$ and on $\left(Y^{2 \infty}, \mathbb{B}\left(Y^{2 \infty}\right)\right)$ specify these processes to be i.i.d. with the probability of $y_{t}^{1}=1$ being $\alpha_{1}$ and the probability of $y_{t}^{2}=1$ being $\alpha_{2}$.

The state space is $\left(X \times \Theta \times Y^{1} \times Y^{2}\right)$ but we can consider this space to be the index set $S=\{1,2, \ldots, 16\}$. We thus write down a new equilibrium map $\Phi$ 
between the indices of prices and the states of monetary policy, of productivity shock and of assessment variables ${ }^{6}$ :

$$
\left[\begin{array}{l}
1 \\
2 \\
3 \\
4 \\
5 \\
6 \\
7 \\
8 \\
9 \\
10 \\
11 \\
12 \\
13 \\
14 \\
15 \\
16
\end{array}\right]=\Phi\left[\begin{array}{llll}
x=x^{H} & \theta=\theta^{H} & y^{1}=1 & y^{2}=1 \\
x=x^{H} & \theta=\theta^{H} & y^{1}=1 & y^{2}=0 \\
x=x^{H} & \theta=\theta^{H} & y^{1}=0 & y^{2}=1 \\
x=x^{H} & \theta=\theta^{H} & y^{1}=0 & y^{2}=0 \\
x=x^{L} & \theta=\theta^{H} & y^{1}=1 & y^{2}=1 \\
x=x^{L} & \theta=\theta^{H} & y^{1}=1 & y^{2}=0 \\
x=x^{L} & \theta=\theta^{H} & y^{1}=0 & y^{2}=1 \\
x=x^{L} & \theta=\theta^{H} & y^{1}=0 & y^{2}=0 \\
x=x^{H} & \theta=\theta^{L} & y^{1}=1 & y^{2}=1 \\
x=x^{H} & \theta=\theta^{L} & y^{1}=1 & y^{2}=0 \\
x=x^{H} & \theta=\theta^{L} & y^{1}=0 & y^{2}=1 \\
x=x^{H} & \theta=\theta^{L} & y^{1}=0 & y^{2}=0 \\
x=x^{L} & \theta=\theta^{L} & y^{1}=1 & y^{2}=1 \\
x=x^{L} & \theta=\theta^{L} & y^{1}=1 & y^{2}=0 \\
x=x^{L} & \theta=\theta^{L} & y^{1}=0 & y^{2}=1 \\
x=x^{L} & \theta=\theta^{L} & y^{1}=0 & y^{2}=0
\end{array}\right] .
$$

Given the map (28) we refer to states $\theta^{H}\left(\theta^{L}\right)$ for $s=1,2, \ldots, 8(s=9,10, \ldots, 16)$ as states of high (low) exogenous productivity shock. We refer to states $x^{H}\left(x^{L}\right)$ for $s=1, \ldots, 4,9, \ldots, 12(s=5, \ldots, 8,13, \ldots, 16)$ as states of loose (tight) monetary policy.

We proceed to construct the RBE by specifying the Markov transition matrix representing the stationary measure as follows

$$
\Gamma=\left[\begin{array}{cccc}
\vartheta \chi A & \vartheta(1-\chi) A & (1-\vartheta) \chi A & (1-\vartheta)(1-\chi) A \\
\vartheta(1-\chi) B & \vartheta \chi B & (1-\vartheta)(1-\chi) B & (1-\vartheta) \chi B \\
(1-\vartheta) \chi C & (1-\vartheta)(1-\chi) C & \vartheta \chi C & \vartheta(1-\chi) C \\
(1-\vartheta)(1-\chi) D & (1-\vartheta) \chi D & \vartheta(1-\chi) D & \vartheta \chi D
\end{array}\right]
$$

which has $\pi=\left(\pi_{1}, \ldots, \pi_{16}\right)$ as its stationary distribution and where $(A, B, C, D)$ are all $4 \times 4$ matrices characterized by the 18 parameters $\left(\alpha_{1}, \alpha_{2}, a, b, c, d\right)$, where $a=\left(a_{1}, a_{2}, a_{3}, a_{4}\right), b=\left(b_{1}, b_{2}, b_{3}, b_{4}\right), c=\left(c_{1}, c_{2}, c_{3}, c_{4}\right), d=\left(d_{1}, d_{2}, d_{3}, d_{4}\right)$, and of the following type:

$$
A=\left[\begin{array}{cccc}
a_{1} & \alpha_{1}-a_{1} & \alpha_{2}-a_{1} & 1+a_{1}-\alpha_{1}-\alpha_{2} \\
a_{2} & \alpha_{1}-a_{2} & \alpha_{2}-a_{2} & 1+a_{2}-\alpha_{1}-\alpha_{2} \\
a_{3} & \alpha_{1}-a_{3} & \alpha_{2}-a_{3} & 1+a_{3}-\alpha_{1}-\alpha_{2} \\
a_{4} & \alpha_{1}-a_{4} & \alpha_{2}-a_{4} & 1+a_{4}-\alpha_{1}-\alpha_{2}
\end{array}\right]
$$

${ }^{6}$ Note that the map $\Phi$ is not the equilibrium map $\Phi^{*}$ which defines the values prices take in equilibrium but rather a map between the indices of the price states $1,2, \ldots, 16$ and the vectors of exogenous states and states of beliefs. 
From (29) and (30) it follows that the marginals of $\Gamma$ are indeed as specified in assumption 10. In fact, the marginal measures $\Gamma_{Y^{k}}$ specify $y_{t}^{k}$ to be i.i.d. with $P\left\{y_{t}^{k}=1\right\}=\alpha_{k}$ for $k=1,2$ and the marginal measures $\Gamma_{X}$ and $\Gamma_{\Theta}$ are specified by the stationary Markov processes (27). Also, although each process $\left\{y_{t}^{k}, t=1,2, \ldots\right\}$ for $k=1,2$ is very simple, the joint process may be complex and allow joint correlation among the $y_{t}^{k}$ over time.

\subsubsection{Equilibrium conditions in terms of price states.}

Given the price state space defined in (28) we can then write the system of Euler equations, the budget constraints and the market clearing conditions in the form used in the computations below (for $s=1,2, \ldots, 16, j=1,2, \ldots, 16$ and $k=1,2$ ). Equations (21)-(23) in terms of price states are respectively written as follows ${ }^{7}$ :

$$
\begin{gathered}
c_{s, j}^{k}=\frac{\theta_{s}\left(1-l_{s}^{k}\right) p_{s} x_{j}}{p_{j} x_{s}} \\
\left(\frac{1-l_{s}^{1}}{l_{s}^{1}}\right)^{\gamma}=\left(\frac{\theta_{s} p_{s}}{x_{s}}\right)^{1-\gamma} \beta \sum_{j=1}^{16}\left(\frac{x_{j}}{p_{j}}\right)^{1-\gamma} Q_{1_{(s, j)}^{s}}^{s} \\
\left(\frac{1-l_{s}^{2}}{l_{s}^{2}}\right)^{\gamma}=\left(\frac{\theta_{s} p_{s}}{x_{s}}\right)^{1-\gamma} \beta \sum_{j=1}^{16}\left(\frac{x_{j}}{p_{j}}\right)^{1-\gamma} Q_{2_{(s, j)}}^{s} .
\end{gathered}
$$

And the market clearing conditions become:

$$
p_{s} \theta_{s}\left(2-l_{s}^{1}-l_{s}^{2}\right)=x_{s} .
$$

We now turn to specify the probabilities $Q_{1}^{s}$ and $Q_{2}^{s}$ of the two agent-types to complete the specification of the equilibria described by the system of equations (31)-(34).

\subsubsection{Rational beliefs.}

By assumption 3 the beliefs of the agents are probabilities of joint Markov process on prices and individual assessment variables. Since by assumption the marginals on the assessment variables are i.i.d. with probabilities $\alpha_{1}$ and $\alpha_{2}$, if we denote the two matrices for agent-type 1 by $\left(F_{1}, F_{2}\right)$ and for agent-type 2 by $\left(G_{1}, G_{2}\right)$, it then follows that the rationality conditions of beliefs are:

$$
\alpha_{1} F_{1}+\left(1-\alpha_{1}\right) F_{2}=\Gamma, \quad \alpha_{2} G_{1}+\left(1-\alpha_{2}\right) G_{2}=\Gamma .
$$

\footnotetext{
${ }^{7}$ Note that to compute equilibrium solutions the system of equations (31)-(34) has been solved using standard Newton method as supplied by the software package TENSOLVE, a suite of FORTRAN 77 subroutines. For a complete overview of the software package TENSOLVE see Bouaricha A. and Schnabel R. B. [4]. All computations have been implemented in FORTRAN 77 on DECStations Sun Ultra Enterprise 5000/200.
} 
Then the following probabilities (where $F_{1}^{s, j}$ is the $(s, j)$ element of $F_{1}$ )

$$
Q_{1_{(s, j)}}^{s}=\left\{\begin{array} { l } 
{ F _ { 1 } ^ { s , j } \text { if } y _ { s } ^ { 1 } = 1 } \\
{ F _ { 2 } ^ { s , j } \text { if } y _ { s } ^ { 1 } = 0 }
\end{array} Q _ { 2 _ { ( s , j ) } ^ { s } } ^ { 1 } \left\{\begin{array}{l}
G_{1}^{s, j} \text { if } y_{s}^{2}=1 \\
G_{2}^{s, j} \text { if } y_{s}^{2}=0
\end{array}\right.\right.
$$

define $Q_{1}^{s}$ and $Q_{2}^{s}$ in (32)-(33). ${ }^{8}$ To complete the definition of $Q_{1_{(s, j)}^{s}}$ and $Q_{2_{(s, j)}}^{s}$ in (36) it is left to specify matrices $\left(F_{1}, F_{2}, G_{1}, G_{2}\right)$. Select 2 parameters $\lambda$ and $\mu$ which will be interpreted later, and define the row vectors of $A$ with the notation

$$
A^{j}=\left(a_{j}, \alpha_{1}-a_{j}, \alpha_{2}-a_{j}, 1+a_{j}-\left(\alpha_{1}+\alpha_{2}\right)\right) j=1,2,3,4 .
$$

Similar notation is used for $B, C$ and $D$. With this notation we define eight matrix functions of a real number $z$ as follows:

$$
\begin{gathered}
A_{1}(z)=\left[\begin{array}{l}
z A^{1} \\
z A^{2} \\
z A^{3} \\
z A^{4}
\end{array}\right], A_{2}^{\vartheta}(z)=\left[\begin{array}{c}
\frac{1-\vartheta z}{1-\vartheta} A^{1} \\
\frac{1-\vartheta z}{1-\vartheta} A^{2} \\
\frac{1-\vartheta z}{1-\vartheta} A^{3} \\
\frac{1-\vartheta z}{1-\vartheta} A^{4}
\end{array}\right] \\
B_{1}(z)=\left[\begin{array}{l}
z B^{1} \\
z B^{2} \\
z B^{3} \\
z B^{4}
\end{array}\right], B_{2}^{\vartheta}(z)=\left[\begin{array}{c}
\frac{1-\vartheta z}{1-\vartheta} B^{1} \\
\frac{1-\vartheta z}{1-\vartheta} B^{2} \\
\frac{1-\vartheta}{1-\vartheta} B^{3} \\
\frac{1-\vartheta}{1-\vartheta} B^{4}
\end{array}\right] \\
C_{1}(z)=\left[\begin{array}{l}
z C^{1} \\
z C^{2} \\
z C^{3} \\
z C^{4}
\end{array}\right], C_{2}^{\vartheta}(z)=\left[\begin{array}{l}
\frac{1-(1-\vartheta) z}{\vartheta} C^{1} \\
z D^{1} \\
z D^{2} \\
z D^{3} \\
z D^{4}
\end{array}\right], D_{2}^{\vartheta}(z)=\left[\begin{array}{l}
\frac{1-(1-\vartheta) z}{\vartheta} C^{2} \\
\frac{1-(1-\vartheta) z}{\vartheta} C^{3} \\
\frac{1-(1-\vartheta) z}{\vartheta} C^{4}
\end{array}\right] \\
D_{1}(z)=\left[\begin{array}{l}
\frac{1-(1-\vartheta) z}{\vartheta} D^{1} \\
\frac{1-\vartheta) z}{\vartheta} D^{2}
\end{array}\right] .
\end{gathered}
$$

\footnotetext{
${ }^{8}$ the superscript in $Q_{1}^{s}$ and $Q_{2}^{s}$ stress the dependence on $y_{s}^{1}$ and $y_{s}^{2}$.
} 
Hence given the definitions (38)-(41) we define the matrices $\left(F_{1}(\lambda), F_{2}(\lambda)\right)$ by

$$
F_{1}(\lambda)=\left[\begin{array}{llll}
\vartheta \chi A_{1}(\lambda) & \vartheta(1-\chi) A_{1}(\lambda) & (1-\vartheta) \chi A_{2}^{\vartheta}(\lambda) & (1-\vartheta)(1-\chi) A_{2}^{\vartheta}(\lambda) \\
\vartheta(1-\chi) B_{1}(\lambda) & \vartheta \chi B_{1}(\lambda) & (1-\vartheta)(1-\chi) B_{2}^{\vartheta}(\lambda) & (1-\vartheta) \chi B_{2}^{\vartheta}(\lambda) \\
(1-\vartheta) \chi C_{1}(\lambda) & (1-\vartheta)(1-\chi) C_{1}(\lambda) & \vartheta \chi C_{2}^{\vartheta}(\lambda) & \vartheta(1-\chi) C_{2}^{\vartheta}(\lambda) \\
(1-\vartheta)(1-\chi) D_{1}(\lambda) & (1-\vartheta) \chi D_{1}(\lambda) & \vartheta(1-\chi) D_{2}^{\vartheta}(\lambda) & \vartheta \chi D_{2}^{\vartheta}(\lambda)
\end{array}\right]
$$

and $F_{2}(\lambda)$ is then defined by the usual condition

$$
F_{2}(\lambda)=\frac{1}{1-\alpha_{1}}\left(\Gamma-\alpha_{1} F_{1}(\lambda)\right)
$$

Finally given the definitions (38)-(41) we define the matrices $\left(G_{1}(\mu), G_{2}(\mu)\right)$ by

$$
G_{1}(\mu)=\left[\begin{array}{llll}
\vartheta \chi A_{1}(\mu) & \vartheta(1-\chi) A_{1}(\mu) & (1-\vartheta) \chi A_{2}^{\vartheta}(\mu) & (1-\vartheta)(1-\chi) A_{2}^{\vartheta}(\mu) \\
\vartheta(1-\chi) B_{1}(\mu) & \vartheta \chi B_{1}(\mu) & (1-\vartheta)(1-\chi) B_{2}^{\vartheta}(\mu) & (1-\vartheta) \chi B_{2}^{\vartheta}(\mu) \\
(1-\vartheta) \chi C_{1}(\mu) & (1-\vartheta)(1-\chi) C_{1}(\mu) & \vartheta \chi C_{2}^{\vartheta}(\mu) & \vartheta(1-\chi) C_{2}^{\vartheta}(\mu) \\
(1-\vartheta)(1-\chi) D_{1}(\mu) & (1-\vartheta) \chi D_{1}(\mu) & \vartheta(1-\chi) D_{2}^{\vartheta}(\mu) & \vartheta \chi D_{2}^{\vartheta}(\mu)
\end{array}\right]
$$

and $G_{2}(\mu)$ is then defined by the usual condition

$$
G_{2}(\mu)=\frac{1}{1-\alpha_{2}}\left(\Gamma-\alpha_{2} G_{1}(\mu)\right)
$$

Given the equilibrium map (28), the Markovian Rational Beliefs structure constructed above allows any revision of the conditional probabilities of states of high exogenous productivity shock $(1,2,3,4,5,6,7,8)$ relative to the stationary measure $\Gamma$, to be offset by an opposite direction revision of the conditional probabilities of states of low exogenous productivity shock $(9,10,11,12,13,14,15,16)$.

In order to ensure non-negative probability entries in $\left(F_{1}, F_{2}, G_{1}, G_{2}\right)$, the selection of the parameters $\lambda$ and $\mu$ is restricted by 10 inequality constraints which define the feasible region. These constraints are as follows:

$$
\begin{aligned}
& \lambda \leq \frac{1}{\vartheta}, \quad \lambda \leq \frac{1}{1-\vartheta}, \quad \lambda \leq \frac{1}{\alpha_{1}}, \quad \lambda \geq \frac{\alpha_{1}+\vartheta-1}{\vartheta \alpha_{1}}, \quad \lambda \geq \frac{\alpha_{1}-\vartheta}{(1-\vartheta) \alpha_{1}} \\
& \mu \leq \frac{1}{\vartheta}, \quad \mu \leq \frac{1}{1-\vartheta}, \quad \mu \leq \frac{1}{\alpha_{2}}, \quad \mu \geq \frac{\alpha_{2}+\vartheta-1}{\vartheta \alpha_{2}}, \quad \mu \geq \frac{\alpha_{2}-\vartheta}{(1-\vartheta) \alpha_{2}} .
\end{aligned}
$$

To motivate these construction note that the parameters $\lambda$ and $\mu$ are multiplied by the rows of $A, B, C$ and $D$ and hence are proportional changes of the conditional probabilities of the four sets of four states $(1,2,3,4),(5,6,7,8)$, $(9,10,11,12)$ and $(13,14,15,16)$ relative to the stationary measure represented by the matrix $\Gamma$ in (29). Since $\lambda$ and $\mu$ are the factors of proportionality by which 
agents' conditional probability beliefs deviate from the stationary probabilities in $\Gamma$, we refer to them as intensity parameters. So far agents' assessment variables have been used to endogenously enlarge the price state space and no actual economic meaning has been attached to them. They attain meaning only when the agents specify how they interpret these variables in generating their conditional probability beliefs. For example, $\lambda>1$ implies increased probabilities of states $(1,2,3,4)$ and $(5,6,7,8)$ in $F_{1}$ relative to $\Gamma$ of agent-type 1 given an initial state $s$ and by the rationality conditions (35) the probabilities of the same states are decreased in $F_{2}$. This means that the assessment variables induce more optimism or pessimism about the occurrence of prices $(1,2,3,4)$ and $(5,6,7,8)$ at $t+1$ relative to $\Gamma$. Suppose that at some date $t$ state $s=1$ occurs so that the price $p_{1}$ is realized. If $\lambda>1$ then agent-type 1 with assessment variable $y_{t}^{1}=1$ uses matrix $F_{1}$ to forecast prices at $t+1$ and by (38)-(41) he is more optimistic (relative to $\Gamma)$ about the probabilities of $\left(p_{1}, p_{2}, p_{3}, p_{4}, p_{5}, p_{6}, p_{7}, p_{8}\right)$ at $t+1$. The converse applies when $y_{t}^{1}=0$. Suppose agent 1 is an optimist using $F 1$. As $\lambda>1$ increases probabilities in $F 1$, the rationality conditions $(35) \alpha_{1} F_{1}+\left(1-\alpha_{1}\right) F_{2}=\Gamma$ require a downward adjustment of the probabilities of $\left(p_{1}, p_{2}, p_{3}, p_{4}, p_{5}, p_{6}, p_{7}, p_{8}\right)$ in the pessimistic matrix $F 2 .^{9}$

The simulations focus on the factors and the conditions under which the Markov monetary economy at study exhibits endogenous uncertainty hence money non-neutrality. There are two such factors:

1. Deviations over time of the intensity parameters $(\lambda, \mu)$ from 1 reflecting the non-stationarity of beliefs of the agents.

2. Correlation among agents represented by the vectors $(a, b, c, d)$ of parameters inducing a joint distribution of the assessments which is Markov and not i.i.d.

The results reported below are focused on studying the characteristics of the joint effects of monetary policy and beliefs on inflation, labor supply and real output.

For any transition of the economy from state $s$ to state $j$ the inflation rates defined by (9) and the rates of return on labor defined by (10) are respectively written as $1+i_{s, j}=\frac{x_{s} p_{j}}{p_{s}}, 1+r_{s, j}=\frac{x_{j} p_{s}}{p_{j} x_{s}}$ for all $s, j=1,2, \ldots, 16$ and respectively

\footnotetext{
${ }^{9}$ Many more complex different structures can be constructed and rational belief equilibria studied. Different patterns of optimism/pessimism may be constructed. Motolese [30] shows that in the case of a markov helicopter type monetary policy there is a particular belief structure that when adopted by all agents it causes no endogenous uncertainty to be present and money to be dynamically neutral. Such a structure implies a perfect correlation between states of optimism/pessimism and monetary policy states. This beliefs structure would be justified if agents learned from the data such a perfect correlation. In other words it would be justified if the data told them that money is neutral. Which empirically is a questionable result. But again, this conclusion is valid only when the monetary policy takes place through proportional transfers.
} 
approximated by $i_{s, j} \approx \ln \left(1+i_{s, j}\right)$ and $r_{s, j} \approx \ln \left(1+r_{s, j}\right)$. Let us note that, because the economy at study has a finite number of prices, the long term rate of return on labor $r$ both under REE and RBE is equal to zero and the long term inflation rate $i$ both under REE and RBE is equal to the long term growth rate of money $\left(E_{\Gamma} x_{t}\right)$.

Before reporting the results of our simulations, we first note that in all states $s=1,2, \ldots, 16$ nominal and real variables are jointly affected by the exogenous monetary shocks $x_{s} \in X=\left\{x^{H}, x^{L}\right\}$, the endogenous states of beliefs $\left(y_{s}^{1}, y_{s}^{2}\right) \in$ $Y \times Y=\{(1,1),(1,0),(0,1),(0,0)\}$ and the exogenous productivity shocks $\theta_{s} \in$ $\Theta=\left\{\theta^{H}, \theta^{L}\right\}$. Due to our Markov assumption any transition from $\theta_{s}=\theta^{L}$ to $\theta_{j}=\theta^{H}$ for $s, j=1,2, \ldots, 16$ or viceversa represents a productivity regime switch. When such a regime switch occurs prices and real variables are jointly affected by the productivity shock, the monetary policy and the endogenous states of beliefs. We want then to decompose the standard deviation of each variable under study and subtract from it the effect of the productivity exogenous shocks in order to isolate the compound effect of monetary forces and states of beliefs. In the case of inflation rates, for example, we first compute the following two long term conditional averages with fixed money supply (i.e. $x_{s}=1$ for $s=1,2, \ldots, 16$ ):

$$
\bar{i}_{H L}=\ln \left(E_{\Gamma}\left(1+i_{s, j} \mid \theta_{s}=\theta^{H}, \theta_{j}=\theta^{L}\right)\right)
$$

and

$$
\bar{i}_{L H}=\ln \left(E_{\Gamma}\left(1+i_{s, j} \mid \theta_{s}=\theta^{L}, \theta_{j}=\theta^{H}\right)\right) .
$$

Now let $\varpi_{s, j}^{H L}=1$ when $\theta_{s}=\theta^{H}, \theta_{j}=\theta^{L}$ and 0 otherwise, and let $\varpi_{s, j}^{L H}=1$ when $\theta_{s}=\theta^{L}, \theta_{j}=\theta^{H}$ and 0 otherwise. Hence the inflation rates volatility, which is the solely joint effect of state of beliefs and monetary policy, will be defined by the standard deviation of the following random variable (for all $s, j=1,2, \ldots, 16$.):

$$
\iota_{s, j}=i_{s, j}-\bar{i}_{H L} \varpi_{s, j}^{H L}-\bar{i}_{L H} \varpi_{s, j}^{L H} .
$$

Similarly we compute the two long term conditional rates of return on labor $\left(\bar{r}_{H L}\right.$ and $\left.\bar{r}_{L H}\right)$ and study the impact of states of beliefs and monetary policy on expected real wage rates by the statistics of the following random variable (for all $s, j=1,2, \ldots, 16$.):

$$
\rho_{s, j}=i_{s, j}-\bar{r}_{H L} \varpi_{s, j}^{H L}-\bar{r}_{L H} \varpi_{s, j}^{L H} .
$$

We can now state the following:

Definition 11 Money is dynamically neutral if, for any transition of the economy from state $s$ to state $j(s, j=1,2, \ldots, 16)$ any monetary shock $x \in X=$ $\left\{x^{H}, x^{L}\right\}$ leaves all real variables unaffected and leads to the following:

$$
1+\iota_{s, j}=x_{s} \text { for all } s, j=1,2, \ldots, 16 .
$$

(i.e. within any given real exogenous shock regime the growth rate of money is the sole determinant of the rate of inflation). 
To measure the pure effect of monetary policy and states of beliefs on output fluctuations we also compute the output deviations from the conditional means $\bar{\Omega}_{H}=E_{\Gamma}\left(\Omega_{s} \mid \theta_{s}=\theta^{H}\right)$ and $\bar{\Omega}_{L}=E_{\Gamma}\left(\Omega_{s} \mid \theta_{s}=\theta^{L}\right)$. This component is uncorrelated with the exogenous productivity shocks and represents the compound effect of Endogenous Uncertainty and monetary policy. To measure this effect let $\zeta_{s}^{H}=1$ when $\theta_{s}=\theta^{H}$ and 0 otherwise, and let $\zeta_{s}^{L}=1$ when $\theta_{s}=\theta^{L}$ and 0 otherwise. Now we can define the output deviations by the following random variable (for all $s=1,2, \ldots, 16$.):

$$
\omega_{s}=\Omega_{s}-\bar{\Omega}_{H} \zeta_{s}^{H}-\bar{\Omega}_{L} \zeta_{s}^{L} .
$$

\subsection{Results of the simulations.}

\subsubsection{The parameterization.}

Utility Function. In all simulations we assume that $\beta=0.92$, the coefficients of relative risk aversion are assumed to be $\gamma=3.5$.

The Exogenous Stochastic Processes. In all simulations we set $\vartheta=0.43$ and $\chi=0.5$. The exogenous productivity shock state space is set to be $\Theta=$ $\left\{\theta^{H}, \theta^{L}\right\}=\{1.3,0.7\}$ and the money growth state space is set to be $X=$ $\left\{x^{H}, x^{L}\right\}=\{1.02,0.98\}$.

The parameters above will remain unchanged across the different simulation cases below unless explicitly specified.

The benchmark case: REE. We define the benchmark case when all agents hold rational expectations. Note that the joint process $\left\{\left(x_{t}, \theta_{t}, y_{t}^{1}, y_{t}^{2}\right), t=1,2, \ldots\right\}$ allows correlation among the four variables over time and such correlation effect plays a central role in the simulations. However, if we set $\alpha_{1}=\alpha_{2}=0.5$ and $a_{i}=b_{i}=c_{i}=d_{i}=0.25$ for $i=1,2,3,4$ then all correlations among the four variables of the joint process are eliminated. If, in addition, we assume that agents ignore their assessment variables and set their beliefs by selecting $Q_{1_{(s, j)}}=Q_{2_{(s, j)}}=\Gamma_{(s, j)} \quad \forall s, j$, then we have exactly the REE of Lucas [25]. In the benchmark case of rational expectations the intensity parameters are required to be $\lambda=\mu=1$. It is easy to see that in such case there is no endogenous uncertainty and that in equilibrium only four possible values of prices, $p_{H H}^{\Gamma}$, $p_{L H}^{\Gamma}, p_{H L}^{\Gamma}$ and $p_{L L}^{\Gamma}$, respectively associated with the exogenous states regimes $\left\{\left(x^{H} \theta^{H}\right),\left(x^{L} \theta^{H}\right),\left(x^{H} \theta^{L}\right),\left(x^{L} \theta^{L}\right)\right\}$, will be realized.

$\underline{R B E}$. In all simulations we set $\alpha_{1}=\alpha_{2}=0.57$. The vectors of correlation parameters are set to $a=b=c=d=(0.20,0.14,0.14,0.14)$ while the intensity parameters $\lambda_{s}$ and $\mu_{s}$ for $s=1,2, \ldots, 16$ and will be accordingly specified later.

Note that we are not attempting to calibrate the model so to simulate the behavior of any given country economy. We are only trying to show how money non-neutrality arises in a RBE and how this differs from a REE. In the tables 
below we report statistics on inflation rates $(\iota)$, rates of return on labor $(\rho)$, level of output $(\Omega)$ for the economy and output deviations from conditional means $(\omega)$. Additionally we report expected aggregate output, inflation rate, wage rate and output deviations conditional upon the occurrence of both a loose and a tight monetary policy (i.e. respectively conditional upon $x_{s}=x^{H}$ and $x_{s}=x^{L}$ ).

\subsubsection{Characteristics of money neutrality in a REE.}

Under any REE of the model money is neutral. The choice of the exogenous monetary shock parameters $\left\{x^{H}, x^{L}\right\}=\{1.02,0.98\}$ imply the long term growth rate of money $\left(E_{\Gamma} x_{t}\right)$ to be equal to zero. It follows that long run neutrality of money is achieved under the REE and the RBE of the model. In other words $\mathrm{RBE}$ are neutral on average. However, money is generically non-neutral in the short run.

Table 1: Characteristics of money (non)-neutrality.

\begin{tabular}{lccrc}
\hline & \multicolumn{2}{c}{ REE } & \multicolumn{2}{c}{ RBE (Case 1) } \\
\hline & avg & $\sigma$ & \multicolumn{1}{c}{$\sigma$ avg } & $\sigma$ \\
\hline$\iota_{t}$ & 0.0000 & 0.0200 & 0.0000 & 0.0503 \\
$\iota_{t} \mid x_{t}=x^{H}$ & 0.0000 & 0.0200 & 0.0165 & 0.0344 \\
$\iota_{t} \mid x_{t}=x^{L}$ & 0.0000 & 0.0200 & -0.0169 & 0.0577 \\
$\rho_{t}$ & 0.0000 & 0.0000 & 0.0000 & 0.0529 \\
$\rho_{t} \mid x_{t}=x^{H}$ & 0.0000 & 0.0000 & -0.0167 & 0.0381 \\
$\rho_{t} \mid x_{t}=x^{L}$ & 0.0000 & 0.0000 & 0.0167 & 0.0600 \\
$\Omega_{t}$ & 1.0248 & 0.2623 & 1.0188 & 0.2699 \\
$\Omega_{t} \mid x_{t}=x^{H}$ & 1.0248 & 0.2623 & 1.0334 & 0.2655 \\
$\Omega_{t} \mid x_{t}=x^{L}$ & 1.0248 & 0.2623 & 1.0041 & 0.2735 \\
$\omega_{t}$ & 0.0000 & 0.0000 & 0.0000 & 0.0330 \\
$\omega_{t} \mid x_{t}=x^{H}$ & 0.0000 & 0.0000 & 0.0147 & 0.0024 \\
$\omega_{t} \mid x_{t}=x^{L}$ & 0.0000 & 0.0000 & -0.0147 & 0.0417 \\
\hline
\end{tabular}

We report in columns 2 and 3 of Table 1 the REE results which provide a reference point for the study of the characteristics of inflation and non-neutrality of money under RBE. From Table 1 one can see the well known result of money neutrality under the Rational Expectations hypothesis. In fact, definition 11 is satisfied: the average inflation rate is equal to the average growth rate of money (i.e. zero), for all states $s, j=1,2, \ldots, 16.1+\iota_{s, j}=x_{s}$ and its standard deviation exactly matches the one implied by the growth rate of money $x_{s}$. All real variables in the economy are not correlated with monetary policy. Their conditional expected values do not depend upon $x \in\left\{x^{H}, x^{L}\right\}$. In the REE any monetary fluctuation leaves the real economy unaffected. In fact, the average level of output is not responsive to monetary forces and exhibits a long term standard deviation exclusively induced by the labor productivity shocks $\theta_{t}$. The last conclusion we 
can draw from the Rational Expectations results is that monetary fluctuations, due to the structural knowledge implied in such equilibrium, do not offer any opportunity for positive returns on labor. In fact, the conditional expected rates of return are equal to zero. Indeed, all the results reported in the REE columns of Table 1 are well known and constitute the hallmark of money neutrality.

\subsubsection{Characteristics of money non-neutrality in a RBE.}

We now turn to the results obtained in the RBE simulations. Our main aim is to explore if heterogeneous rational beliefs can expand(contract) the effect of monetary policy causing endogenous fluctuations in output and employment and affecting price volatility in contrast to the neutrality property of REE of Table 1. To characterize the structure of beliefs we have to choose the intensity parameters $\lambda$ and $\mu$. We thus start considering the following pattern of intensity parameters which we name as Case 1 or $x^{H}$-consensus:

$$
\begin{aligned}
& \lambda_{s}=\mu_{s}=1.0000 \text { for } s=1,2,3,4,9,10,11,12 \\
& \lambda_{s}=\mu_{s}=1.7542 \text { for } s=5,6,7,8,13,14,15,16 .
\end{aligned}
$$

The results obtained under this pattern of beliefs are reported in the RBE columns of Table 1. From that table we can immediately see that RBE are drastically different than REE. Monetary forces are not neutral and have a non trivial impact on the real sector of the economy as well as on inflation. Monetary shocks have an effect on expectations of agents and although they observe the current growth rate of money $x_{t}$, their demand for money and their labor supply (which depend upon their beliefs) change according to their interpretation of the monetary signal. This results in a percentage change in the price level not equal to the growth rate of money (i.e. money is dynamically non-neutral). Monetary policy under RBE is perceived as a signal that carries information about future price levels hence inflation rates and wage rates which is not the case under REE.

Before further discussing the results reported in Table 1 we need to get some intuition about the pattern of intensity parameters in (50). Recall the equilibrium map (28) in which the states $x_{s}^{H}\left(x_{s}^{L}\right)$ for $s=1, \ldots, 4,9, \ldots, 12(s=5, \ldots, 8,13, \ldots, 16)$ are states of loose (tight) monetary policy. Bear in mind that $\alpha_{1}=\alpha_{2}=0.57$ means that both agents are optimistic in $57 \%$ of the dates and that $\lambda=\mu=$ 1.7542 is the maximal ratio, implied by the feasibility conditions (46), by which, when optimistic, agents can adjust probabilities of states $s=1, \ldots, 8$ at $t+1$ which are the states of low price and high output levels. On the other hand $\lambda=\mu=1$ means that agents believe in the stationary measure $\Gamma$ thus realizing an overall consensus among them with no states of optimism or pessimism. Note that the intensity parameters $\lambda_{s}=\mu_{s}=1$ from (50) are associated with states

of loose monetary policy (i.e. $x_{t}=x^{H}$ ) while $\lambda_{s}=\mu_{s}=1.7542$ are associated with states of tight monetary policy (i.e. $x_{t}=x^{L}$ ). It follows that when $x_{t}=x^{H}$ agents' expectations are in accord with the stationary measure resulting in a 
perfect consensus. When $x_{t}=x^{L}$ states of disagreement among agents occur. Notice that the parameter choice in (50) along with the choice of the correlation parameters $a=b=c=d=(0.20,0.14,0.14,0.14)$ and $\alpha_{1}=\alpha_{2}=0.57$ imply that states of optimism and pessimism are asymmetric.

The implications of the $x^{H}$-consensus structure are such that $\Omega_{t} \mid x_{t}=x^{H}$ is higher than $\Omega_{t} \mid x_{t}=x^{L}$. In fact when $x_{t}=x^{L}$ agents' expectations are pushed to the extreme and with high probability they forecast less inflation and high wage rates and so their labor supply is higher. However, the pessimists in the economy are almost sure that high inflation and low wage rates will occur at date $t+1$ and work less and push down the total output $\Omega_{t} \mid x_{t}=x^{L}$. The intensity level of pessimism dominates and hence aggravates the occurrence of crashes or recession periods ${ }^{10}$. Monetary policy under Rational Beliefs does have an impact on the real variables as it influences the terms of trade between the present and the future. It is also the case under Rational Beliefs that the rational mistakes of the agents can amplify or reduce the effect of monetary policy leading to a higher standard deviation of inflation rates than under Rational Expectations. Also the long term rates of return on labor under Rational Beliefs exhibit higher standard deviations than under Rational Expectations.

We report in Figures 1 and 2 respectively samples of 300 observations of equilibrium inflation rates $(\iota)$ and rates of return $(\rho)$ generated by Montecarlo simulations under the $x^{H}$-consensus structure.

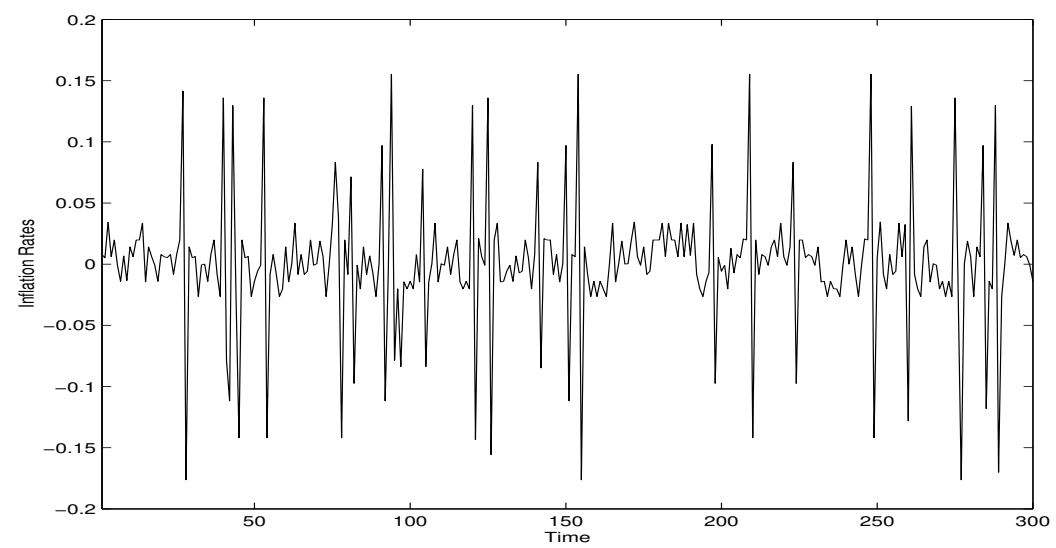

Figure 1: Inflation Rates under Rational Beliefs (Case 1).

We now consider a pattern of rational beliefs which is symmetric in the choice of intensity parameters to the one examined above and exhibits quite the opposite behavior in the statistics. The following choice of beliefs parameters identifies

\footnotetext{
${ }^{10}$ The parameters choice and the interpretation of the implied dynamics is similar to that of Kurz and Motolese [22] in explaining the equity premium and stock prices dynamics.
} 


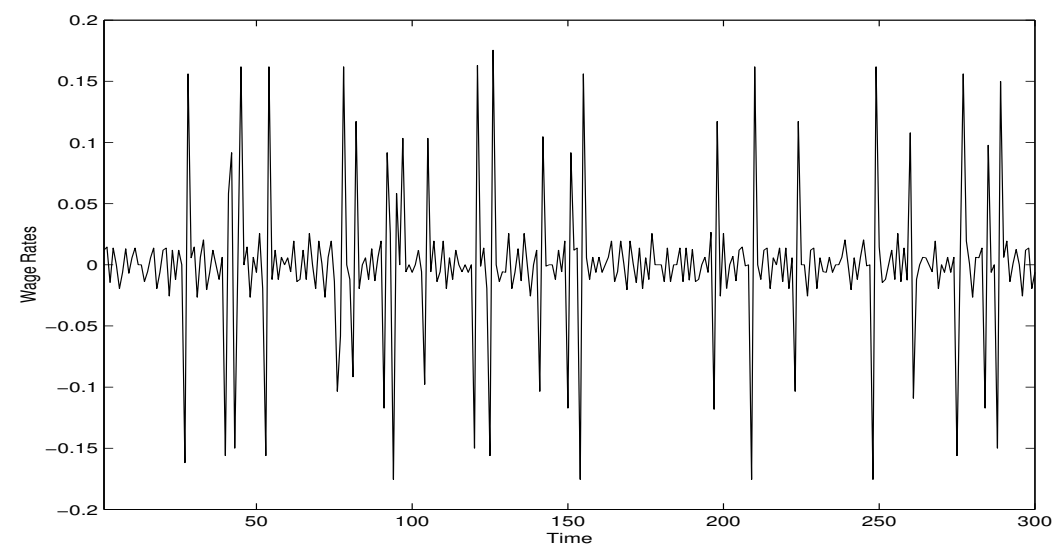

Figure 2: Wage Rates under Rational Beliefs (Case 1).

Case 2 or $x^{L}$-consensus:

$$
\begin{aligned}
& \lambda_{s}=\mu_{s}=1.7542 \text { for } s=1,2,3,4,9,10,11,12 \\
& \lambda_{s}=\mu_{s}=1.0000 \text { for } s=5,6,7,8,13,14,15,16 .
\end{aligned}
$$

The results obtained under this pattern of beliefs are reported in Table 2 .

Table 2: Characteristics of money non-neutrality.

\begin{tabular}{lrc}
\hline & \multicolumn{2}{c}{ RBE $($ Case 2$)$} \\
\hline$\iota_{t}$ & \multicolumn{1}{c}{ avg } & \multicolumn{1}{c}{$\sigma$} \\
$\iota_{t} \mid x_{t}=x^{H}$ & 0.0000 & 0.0622 \\
$\iota_{t} \mid x_{t}=x^{L}$ & -0.0169 & 0.0683 \\
$\rho_{t}$ & 0.0165 & 0.0502 \\
$\rho_{t} \mid x_{t}=x^{H}$ & 0.0000 & 0.0529 \\
$\rho_{t} \mid x_{t}=x^{L}$ & 0.0167 & 0.0600 \\
$\Omega_{t}$ & -0.0167 & 0.0381 \\
$\Omega_{t} \mid x_{t}=x^{H}$ & 1.0188 & 0.2699 \\
$\Omega_{t} \mid x_{t}=x^{L}$ & 1.0041 & 0.2735 \\
$\omega_{t}$ & 1.0334 & 0.2655 \\
$\omega_{t} \mid x_{t}=x^{H}$ & 0.0000 & 0.0330 \\
$\omega_{t} \mid x_{t}=x^{L}$ & -0.0147 & 0.0417 \\
& 0.0147 & 0.0024 \\
\hline
\end{tabular}

From Table 2 we can immediately notice the reversed behavior in the reported statistics of the $x^{L}$-consensus belief structure with respect to that of Case 1 . In fact, conditional on a loose monetary policy the expected rate of inflation is below average as well as the expected output while the wage rate is above average. The contrary occurs when conditioning on a tight monetary policy. Also notice that, despite the symmetry in the choice of the intensity parameters $\lambda$ and $\mu$, due to the 
asymmetric dynamics of states of optimism and pessimism, under this pattern of rational beliefs the joint effect of monetary policy and agents' expectations induces a higher volatility in inflation rates. We report in Figure 3 a sample of 300 observations of equilibrium inflation rates $(\iota)$ under the $x^{L}$-consensus structure.

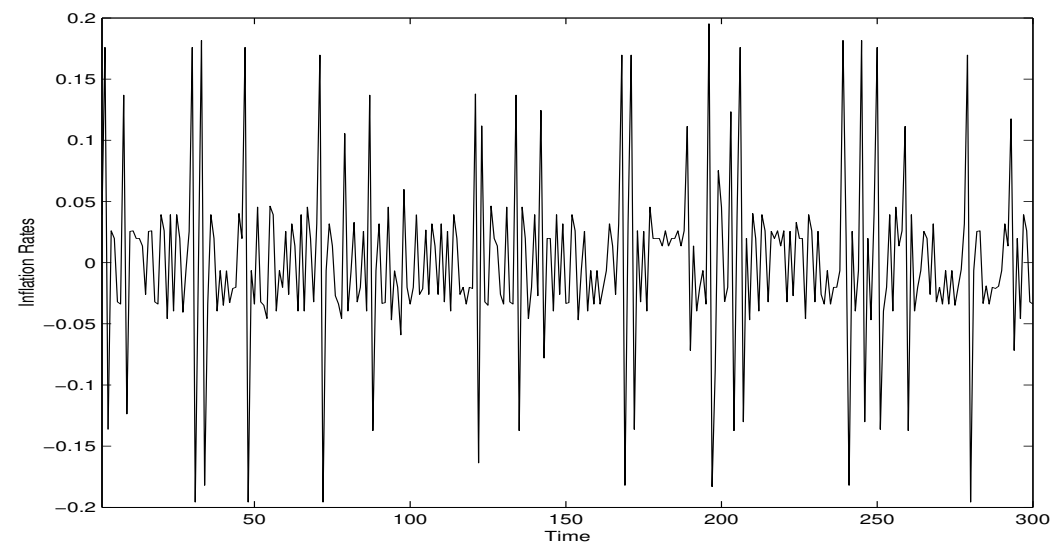

Figure 3: Inflation Rates under Rational Beliefs (Case 2).

Why is money non neutral under RBE? The real effect of money in an $\mathrm{RBE}$ arises from the diversity of beliefs. Monetary shocks have a real effect because agents interpret differently the observed growth rate of money at date $t$ thus inducing diverse forecasts of all variables in the economy at date $t+1$. Agents disagree about the effects of monetary shocks on future inflation, wage rates and output levels. Agent hold diverse forecast of the real variables in the economy and once they disagree on the effects of monetary shocks on future inflation, monetary shocks have real effects. This is analogous to Lucas' [25] case justifying money non-neutrality by agents confusion between monetary and real shocks. However, in an RBE there is no confusion about shocks and all the observables, only diversity of opinions about forecasting future variables and this is sufficient for money to be non neutral. In agreement with the results achieved by Kurz, Jin and Motolese [21] we also assert that once agents perceive money to have real effects, it is rational for them to incorporate monetary shocks as a component affecting their own beliefs about all variables in the economy (i.e. for $x_{t}$ to affect agents' perceptions).

In Tables 1 and 2 we have reported results from two different Rational Beliefs structures. Both of them exhibit money non-neutrality but its behavior goes in two opposite directions. The difference between Table 1 and Table 2 is the quantitative impact of the monetary shock $x_{t}$ : the effect of $x_{H}$ in Table 1 is equal to the effect of $x_{L}$ in Table 2 and vice versa. The first structure $\left(x^{H}\right.$-consensus $)$ presents a pro-cyclical behavior: it shows positive correlation between the growth rate of money and output. The second structure $x^{L}$-consensus, instead, presents 
a counter-cyclical behavior: it shows negative correlation between the growth rate of money and output ${ }^{11}$.

The empirical evidence is compatible with the pro-cyclical rational belief structure, that is, we observe a positive correlation between the growth rate of money and output (see the highly debated issue outlined by Friedman and Schwartz [7] and recently reestablished by Aksoy and Piskorski [1]). Analogous modeling and results have been studied by Kurz, Jin and Motolese [21].

The above conclusion leads to the natural question of whether the structure of beliefs under Case 1 is the actual pattern of beliefs observed in the market. We can not give an answer yet. Further research and availability of market data on expectations is crucial to address this issue. Within the RBE theory a recent paper by Kurz [19] started tackling such a topic following earlier issues raised by Romer and Romer [35].

\section{Real GNP fluctuations and the Phillips Curve.}

Tables 1 and 2 show a very important feature of the RBE under study: some components of real GNP fluctuations in the economy are explained by an endogenous mechanism induced by the distribution of beliefs among agents. Furthermore, GNP fluctuations under the two monetary regimes $x^{H}$ and $x^{L}$ are different thus implying an effective role for monetary policy in the settling of cycles. This is a drastically different scenario compared to the one obtained under Rational Expectations where the monetary forces play no role at all to explain GNP fluctuations and cycles. The distribution of beliefs in the economy at any date is a crucial factor which constitutes an endogenous components of output fluctuations. This is one of the most important conclusions we can draw from the results shown above. To support the argument above we have also reported in Tables 1 and 2 statistics for output deviations from the conditional means $(\omega)$ within each monetary regime. This component is uncorrelated with the exogenous productivity shocks and represents the compound effect of Endogenous Uncertainty and monetary policy. In figure 4, a time series realization of 300 observations of output deviations is plotted. From figure 4 we can immediately see that in a RBE the distribution of beliefs creates Endogenous Fluctuations of Output which are not generated under REE. Such fluctuations take the form of crashes and booms or of recession and expansion periods. From Figure 4 as well as from Tables 1 and 2 we notice that negative deviations (crashes) have larger standard deviations then positive deviations (booms). In other words they are not symmetric. Once again this is due to the asymmetric behavior of states of optimism and pessimism as explained above. The intensity of the pessimists dominates and it is just counterbalanced by a less intense level of optimism and this pushes the level of output

\footnotetext{
${ }^{11}$ The sign of such a correlation under both cases is also respectively confirmed by the regression coefficients of the growth rate of money $x_{t}$ in the Phillips curves (52) and (53).
} 


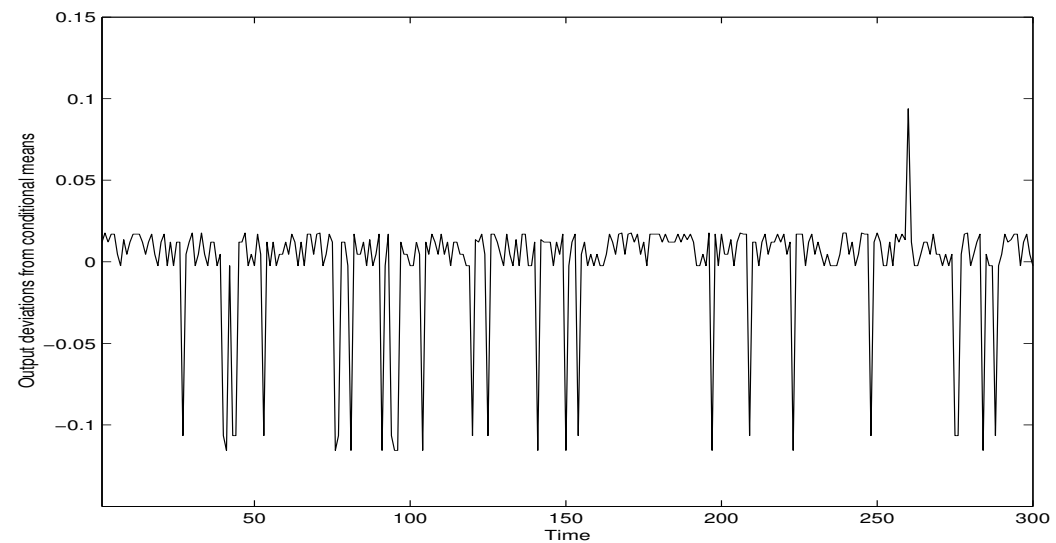

Figure 4: Endogenous Output fluctuations under Rational Beliefs.

down to recession. We thus conclude that under Rational Beliefs recessions can be substantially aggravated by the distribution of market beliefs.

To strengthen the RBE result of money non-neutrality we also simulated the economy and generated 10,000 observations and estimated the following basic and simple regression model:

$$
\Omega_{t}=\delta_{0}+\delta_{1} E_{t, \Gamma \mid p_{t}}\left(\iota_{t+1}\right)+\delta_{2} x_{t}+\delta_{3} \theta_{t}+\epsilon_{t}
$$

where $E_{t, \Gamma \mid p_{t}}\left(\iota_{t+1}\right)$ is the $t+1$ expected inflation rate conditional upon the state price $p_{t}$ observed at $t$ measured by the stationary probability $\Gamma$. We obtained the following estimation for the RBE Case 1:

$$
\Omega_{t}=\underset{(0.0050)}{0.0940}+\underset{(0.0026)}{0.8399} E_{t, \Gamma \mid p_{t}}\left(\iota_{t+1}\right)+\underset{(0.0050)}{0.0319} x_{t}+\underset{(0.0003)}{0.8930} \theta_{t}+\epsilon_{t}, \quad R^{2}=0.999,
$$

and the following estimation for the RBE Case 2:

$$
\Omega_{t}=\underset{(0.0049)}{0.1556}+\underset{(0.0026)}{0.8358} E_{t, \Gamma \mid p_{t}}\left(\iota_{t+1}\right) \underset{(0.0049)}{0.0296} x_{t}+\underset{(0.0003)}{0.8931} \theta_{t}+\epsilon_{t}, \quad R^{2}=0.999
$$

In both regressions the Phillips curve coefficient of $E_{t, \Gamma \mid p_{t}}\left(\iota_{t+1}\right)$ is positive. In the regression of Case 1 the sign of the coefficient of the growth rate of money $x_{t}$ is also positive which stresses the positive correlation between monetary regimes and GNP we already highlighted in Table 1 . On the contrary in the regression of Case 2 the sign of the coefficient of the growth rate of money $x_{t}$ is negative as expected given the negative correlation between monetary regimes and GNP we already found in Table 2 .

We thus conclude that the non-zero slope of the Phillips Curves above is due to the endogenous distribution of beliefs in the economy. Furthermore, such a result is consistent with those of Kurz, Jin and Motolese [21] where also further implications of the role of monetary policy under RBE are discussed. 


\section{Conclusions.}

In this paper we have demonstrated that dynamic money non-neutrality is a generic property of any RBE. Endogenous uncertainty is the main force generating money non-neutrality. Endogenous uncertainty is the dominant uncertainty in an RBE. Such a form of uncertainty is that component of market volatility which is generated by the diversity of agent's beliefs. Hence monetary forces do have an impact on the real variables of the economy and such an impact can be amplified or reversed by the beliefs of the agents. We studied a two-agent OLG economy similar to the two islands model of Lucas' [25]. We assumed all transaction occur on one single market and no informational asymmetry exists. We showed that the heterogeneity of beliefs together with the distribution and intensity of agents' states of optimism/pessimism can expand or reduce the real effect of monetary policy and generate Endogenous Fluctuations of Output and give rise to higher volatility of inflation rates and wage rates.

We found that under RBE, when agents perceive monetary policy as a signal that carries information about future prices and wage rates, different patterns of volatility are observed in the economy. Such patterns depend upon agents' subjective interpretation of the observed monetary signal and upon the induced optimism/pessimism in their conditional probability beliefs. Furthermore, the non-neutrality of money results in a short run Phillips curve and its non-zero slope is due to the endogenous distribution of beliefs in the economy.

It is clear that the proposed paradigm of the Theory of Rational Beliefs has very important implications to the study of economic fluctuations and to the formulation of monetary policy. For this reason we think that the distribution of market beliefs constitutes useful information for the conduct of monetary policy. The results obtained in the present study and Nielsen [34] represent a first step in addressing the implications of the theory proposed by Kurz [12], [13] to monetary policy. Further implications have already been addressed by Kurz, Jin and Motolese [21] who show under an infinite horizon RBE money non-neutrality, the existence of a short-run Phillips curve and of "hump shaped" impulse response functions with respect to monetary shocks. They also address the very debated issue about the role of monetary policy which under RBE is aimed to reducing the excess endogenously created volatility.

\section{References}

[1] Aksoy, Y., Piskorski, T., Domestic Money and US Output and Inflation. CFS Working Paper 2001/08, Center for Financial Studies an der Johann Wolfgang Goethe-Universität, (2001).

[2] Azariadis, C., A Reexamination of Natural Rate Theory. American Economic Review 71, pp. 944-960, (1981). 
[3] Azariadis, C., Guesnerie, R., Sunspots and Cycles. Review of Economic Studies 53, pp. 725-737, (1986).

[4] Bouaricha, A., Schnabel, R. B., TENSOLVE: A software Package for Solving Systems of Nonlinear Equations and Nonlinear Least Squares Problems Using Tensor Methods. Argonne National Laboratories, Illinois, (1994).

[5] Cass, D., Shell, K., Do sunspots matter? Journal of Political Economy 91, pp. 193-227, (1983).

[6] Chiappori, P. A., Guesnerie, R., Anticipations, indétermination et nonneutralité de la monnaie. Annales d'Economie et de Statistique 19, pp. 1-25, (1990).

[7] Friedman, M., Schwartz, A., A Monetary History of the United States: 18671960, Princeton University Press, Princeton, New Jersey, (1963).

[8] Gurley, J. G., Review of "A program of monetary stability by Milton Friedman", Review of Economics and Statistics 43, pp. 307-308, (1961).

[9] Hoffman, D. L., Schlagenhauf, D. E., An econometric investigation of the monetary neutrality and rationality propositions from an international perspective. Review of Economics and Statistics 64, pp. 562-571, (1982).

[10] Keynes, J. M., A Monetary Theory of Production. First published in 1933. Reprinted in The Collected Writings of John Maynard Keynes, vol. 13. Ed. by D. Moggridge. Macmillan, London, (1973).

[11] Kurz, M., The Kesten-Stigum Model and the Treatment of Uncertainty in Equilibrium Theory. In: Balch, M.S., McFadden, D.L., Wu, S.Y. (eds.), Essays on Economic Behavior Under Uncertainty, pp. 389-399, North Holland, Amsterdam, (1974).

[12] Kurz, M., On the Structure and Diversity of Rational Beliefs. Economic Theory 4, pp. 877-900, (1994).

[13] Kurz, M., On Rational Belief Equilibria. Economic Theory 4, pp. 859-876, (1994).

[14] Kurz, M.(ed), Endogenous Economic Fluctuations: Studies in the Theory of Rational Belief. Studies in Economic Theory, No. 6, Springer-Verlag, Berlin and New York, (1997).

[15] Kurz, M., Asset Prices with Rational Beliefs. In: Kurz, M. (ed.) Endogenous Economic Fluctuations: Studies in the Theory of Rational Belief, Chapter 9. Studies in Economic Theory, No. 6, Springer-Verlag, Berlin and New York, (1997). 
[16] Kurz, M., On the Volatility of Foreign Exchange Rates. In: Kurz, M. (ed.) Endogenous Economic Fluctuations: Studies in the Theory of Rational Belief, Chapter 12. Studies in Economic Theory, No. 6, Springer-Verlag, Berlin and New York, (1997).

[17] Kurz, M., Endogenous Uncertainty: A Unified View of Market Volatility. Working Paper 97-027, Department of Economics, Stanford University, (1997).

[18] Kurz, M., Social States of Belief and the Determinant of the Equity Risk Premium in a Rational Belief Equilibrium. In: Abramovich, Y. A., Avgerinos, E. and Yannelis, N. C., (eds), Functional Analysis and Economic Theory. Springer series in Applied mathematics and Operation Research, pp. 171220, Springer-Verlag, Berlin and New York, (1998).

[19] Kurz, M., Heterogeneous Forecasting and Federal Reserve Information. Working Paper 02-002, Department of Economics, Stanford University, (2002).

[20] Kurz, M., Beltratti, A., The Equity Premium is No Puzzle. In: Kurz, M. (ed.) Endogenous Economic Fluctuations: Studies in the Theory of Rational Belief, Chapter 11. Studies in Economic Theory, No. 6, Springer-Verlag, Berlin and New York, (1997).

[21] Kurz, M., Jin, H., Motolese, M., Endogenous Fluctuations and the Role of Monetary Policy. In, P. Aghion, R. Frydman, J. Stiglitz and M. Woodford, (eds.) Knowledge, Information and Expectations in Modern Macroeconomics: Essays In Honor of Edmund S. Phelps, Princeton University Press, Princeton, N.J., (2002).

[22] Kurz, M., Motolese, M., Endogenous Uncertainty and Market Volatility. Economic Theory 8, pp. 461-488, (1996).

[23] Kurz, M., Schneider, M., Coordination and Correlation in Markov Rational Belief Equilibria. Economic Theory 8, pp. 489-520, (1996).

[24] Kurz, M., Wu, H. M., Endogenous Uncertainty in a General Equilibrium Model with Price Contingent Contracts. Economic Theory 17, pp. 497-544, (2001).

[25] Lucas, Jr., R., Expectations and the Neutrality of Money. Journal of Economic Theory 4, pp. 103-124, (1972).

[26] Lucas, Jr., R., Some International Evidence on Output Inflation Trade-offs. American Economic Review 63, pp. 326-334, (1973). 
[27] Lucas, Jr., R., Expectations and the Neutrality of Money: Corrigendum. Journal of Economic Theory 31, pp. 197-199, (1983).

[28] Lucas, Jr., R., Nobel Lecture: Monetary Neutrality. Journal of Political Economy 104, pp. 661-682, (1996).

[29] Mishkin, F.S., Does anticipated monetary policy matter? An econometric investigation. Journal of Political Economy 90, pp. 22-51, (1982).

[30] Motolese, M., Dynamic Non-neutrality of Money under Rational Beliefs: the Role of Endogenous Uncertainty. A Ph.D. dissertation submitted to the University of Bologna, (November 1998).

[31] Motolese, M., Money non-neutrality in a Rational Belief Equilibrium with financial assets. Economic Theory 18, pp. 97-126, (2001).

[32] Muth, J. F., Rational Expectations and the Theory of Price Movements. Econometrica 29, pp. 315-335, (1961).

[33] Nielsen, C. K., Rational Belief Structures and Rational Belief Equilibria. Economic Theory 8, pp. 399-422, (1996).

[34] Nielsen, C. K., Floating exchange rates versus a monetary union under Rational Beliefs: the role of endogenous uncertainty. Mimeo, Institute of Economics, University of Copenhagen, (1997).

[35] Romer, C. D., Romer, D. H., Federal Reserve Information and the Behavior of Interest Rates. American Economic Review, 90, pp. 429-457, (2000).

[36] Sargent, T. J., Wallace, N., Rational Expectations, the Optimal Monetary Instrument and the Optimal Money Supply Rule. Journal of Political Economy 83, pp. 241-254, (1975).

[37] Woodford, M., Imperfect Common Knowledge and the Effects of Monetary Policy. In, P. Aghion, R. Frydman, J. Stiglitz and M. Woodford, (eds.) Knowledge, Information and Expectations in Modern Macroeconomics: Essays In Honor of Edmund S. Phelps, Princeton University Press, Princeton, N.J., (2002). 